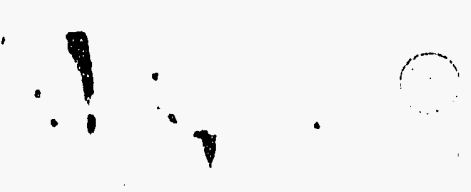

\title{
VIBRATIONAL SPECTROSCOPIC STUDIES OF SURFACE CHEMICAL INTERACTIONS IN CHEMISORPTION AND CATALYSIS DE-FG02-88ER13864
}

John T. Yates, Jr. $\mathrm{DOE} / \mathrm{ER} / 13864--\mathrm{T} 1$ Department of Chemistry Surface Science Center DE92 011189 University of Pittsburgh Pittsburgh, PA 15260

$(412)-624-8320$

\section{PROGRESS/STATUS REPORT-1990-91}

Various methods of vibrational spectroscopy are being employed to stiddy the interaction and behavior of catalytically important species on both single crystal and high area catalytic surfaces. A number of interrelated themes are being investigated as shown below.

\section{MECHANISM OF CATALYTIC REACTIONS}

I. $\mathrm{CH}_{4}$ ACTIVATION MECHANISH ON Ni(111).

A bulb experiment involving the study of carbon deposition from high pressure methane on $N i(111)$ has shown that a direct activation mechanism operates.

II. ETHANOL ACTIVTION MECHANISM ON NI(111).

IRAS $^{\star}$ has been employed to observe the activated decomposition of ethanol on $\mathrm{Ni}(111)$. It has been shown that the scission of the $\mathrm{O}-\mathrm{H}$ bond is accompanied by a reorientation of the molecule to a configuration which is more parallel to the surface. A large deuterium kinetic isotope effect is observed in the $\mathrm{C}-\mathrm{H}$ activation, suggesting that both $\mathrm{O}$ and $\mathrm{H}$ are bound to the surface in the adsorbed ethanol molecule.

\footnotetext{
${ }^{\star}$ IRAS = Infrared Reflection - Absorption Spectroscopy
} 


\section{MOLECULAR INTERACTIONS IN THE ADSORBED LAYER}

\section{OVERLAYER EFFECTS ON THE BEHAVIOR OF CHEMISORBED LAYERS}

IRAS has been used to probe the influence of $\mathrm{NH}_{3}$ adsorbed over chemisorbed $\mathrm{CO}$. It has been found that the electric field induced by $\mathrm{NH}_{3}$ in the $\mathrm{CO}$ layer is able to cause the rehybridization of the chemisorbed $\mathrm{CO}$. This effect is very important in understanding solvent-adsorbate interactions at the electrode surface and represents the first demonstration of these effects in vacuum under conditions where no external potentials has been applied.

II. NITROGEN ADSORPTION ON NI(111).

IRAS has been employed to study the details of the interaction of $\mathrm{N}_{2}$ with the $\mathrm{Ni}(111)$ surface. A strong absorption band due to the $\mathrm{N}-\mathrm{N}$ stretching mode has been observed. As the $N_{2}$ coverage is increased, various surface phases are observed at elevated equilibrium pressures. The highest frequency mode is postulated to be due to nitrogen domain boundaries in which the intermolecular $\mathrm{N}_{2}-\mathrm{N}_{2}$ spacing is smaller than in any other phase. The enthalpy of adsorption has been carefully measured as a function of nitrogen coverage.

III. ELECTRON STIMULATED DESORPTION OF CHEMISORBED CO FOLLOWED BY IRAS.

It has been shown that the terminal and bridged-CO species on $N i(111)$ exhibit very different cross sections for electron stimulated desorption. Terminal bonded $C O$ exhibits a cross section 10 times larger than bridge bonded $\mathrm{CO}$. This is presumably due to enhanced quenching of the excited CO state when it is formed from bridged-co due to the closer distance this species occupies relative to the surface, compared to the projecting terminal-co species. This work represents the first use of IRAS to study electron stimulated desorption, and it demonstrates the detailed insight into ESD mechanisms which may be obtained using the species-sensitive IRAS technique.

IV. POTASSIUM PROMOTED CO CHEMISTRY ON Ni(111).

Laser induced thermal desorption has been employed to measure the kinetics of intermolecular isotopic exchange between $\mathrm{CO}$ molecules in the presence of potassium adsorbate. The reaction proceeds with a low 
activation energy $(72 \mathrm{~kJ} / \mathrm{mol})$, but only to $50 \%$ of the statistical

limit. To explain these phenomena, a potassium etherate intermediate $\left(\mathrm{K}_{2} \mathrm{C}_{2} \mathrm{O}_{2}\right)$ is postulated. (Collaborative work with Professor K. Janda).

\section{CATALYST CHARACTERIZATION AND MODIFICATION}

\section{LIFETIME EXTENSION OF Rh/Al ${ }_{2} \mathrm{O}_{3}$ CATALYSTS}

We have used transmission IR methods to study the modification of $\mathrm{Rh} / \mathrm{Al}_{2} \mathrm{O}_{3}$ catalysts widely used in automotive pollution control. It has been found that $\mathrm{O}-\mathrm{H}$ groups on $\mathrm{Al}_{2} \mathrm{O}_{3}$ are intimately involved as oxidizing agents, converting $\mathrm{Rh}(\mathrm{O})$ to $\mathrm{Rh}(\mathrm{I})$ and producing the easily observed $\mathrm{Rh}(\mathrm{I})(\mathrm{CO})_{2}$ specles. By exchanging the $\mathrm{O}-\mathrm{H}$ groups with $\mathrm{K}^{+}$, this trait for $\mathrm{Rh}(\mathrm{O})$ oxidation is eliminated. It is believe that this effect may lead to an effective method for the extension of cataiyst lifetime in automotive applications. A US PATENT APPLICATION HAS BEEN FILED.

II. VIBRATIONAL COUPLING BETWEEN ETHYLIDYNE SPECIES ON PE CATALYSTS

Using transmission IR methods, we have examined the intermolecular coupling between neighbor $\mathrm{CCH}_{3}$ species on supported Pt surfaces. This has involved the examination of the frequency and intensity of the symmetric $\mathrm{CH}_{3}$ deformation mode of $\mathrm{CCH}_{3}$ for two isotopic species $\left({ }^{2} \mathrm{CH}_{3}\right.$ and $\left.{ }^{13} \mathrm{CH}_{3}\right)$ adsorbed together. It has been determined that the interaction behaves as if the ethylidyne species are present on Pt(111) faces, suggesting that the behavior on these microfaces resembies that on single crystal faces, rather than on randomly distributed $\mathrm{Pt}_{3}$ sites. This work represents the first observation of this couping on catalysts other than the classic work involving chemisorbed co isotopes.

\section{DEVELOPMENT OF NEW SPECTROSCOPIC METHODS}

I. FIRST OPTICAL OBSERVATION OF A VIBRATIONAL OVERTONE FOR AN ADSORBED SPECIES ON A SINGLE CRYSTAL SURFACE

The methoxy species adsorbed on $N i(111)$ has been shown to exhibit a measurable first overtone band for the $\mathrm{C}-0$ stretching mode near $1000 \mathrm{~cm}^{-1}$. This overtone is barely within the detectability of our 
current level of IRAS-FTIR spectroscopy, exhibiting about $2 \%$ of the intensity of the fundamental mode. The measured anharmonicity of the C-O vibrational motion in the methoxy species may be used to estimate the $C-0$ bond dissociation energy in methoxy relative to that in methanol. No evidence of $\mathrm{C}-\mathrm{O}$ bond weakening is observed for the methoxy species.

Publications - $1990-91$

L. Hanley, Z. Xu and J.T. Yates, Jr. "Methane Activation on Ni(111) at High Presures," Surface Science, $\underline{248}$ (1991) 265.

J. Xu, X. Zhang, R. Zenobi, J. Yoshinobu, Z. Xu and J.T. Yates, Jr. "Ethanol Decomposition on $\mathrm{Ni}(111)$-Observation of Ethoxy Formation by IRAS and Other Methods," Surface Science, 256 (1991) 288.

2. Xu, L. Hanley and J.T. Yates, Jr. "Layer Interactions Between dissimilar Adsorbates: $\mathrm{NH}_{3}$ Layers on Chemisorbed $\mathrm{CO}$ on Ni(111)-A Reflection Infrared Study," submitted to J. Chem. Phys.

J. Yoshinobu, R. Zenobi, J. Xu, Z. Xu and J.T. Yates, Jr. "N2 Chemisorption on $\mathrm{Ni}(111)$ - An Infrared Investigation Under Steady-State Conditions," submitted to J. Chem. Phys.

Z. XU and J.T. Yates, Jr. "IRAS Study of ESD Behavior of CO on Ni(111) at 90K," accepted, Surface Science.

K. Sinniah, W.D. Sands, J.T. Yates, Jr. and K.C. Janda "Rate Law and Activation Energy of Isotope Mixing Between Chemisrobed CO Molecules on a K Promoted

$\mathrm{Ni}(111)$ Surface," J. Am. Chem. Soc., 113 (1991) 3684.

M.I. Zaki, T.H. Ballinger, and J.T. Yates, Jr. "Protection of $\mathrm{Rh} / \mathrm{Al}_{2} \mathrm{O}_{3}$ Catalysts by Potassium Functionalization of the $\mathrm{Al}_{2} \mathrm{O}_{3}$ Support," J. Phys. Chem., 95 (1991) 4028.

D.K. Paul, T.P. Beebe, Jr., K.J. Uram and J.T. Yates, Jr. "Vibrational Coupling Between Ethylidyne Species on Platinum Particles", J. Am. Chem. Soc., in press.

R. Zenobi, J. Xu, J.T. Yates, Jr., B.N.J. Persson and A.I. Yolkitin "FTIR Overtone Spectroscopy on Surfaces: The C-O Mode in Chemisorbed Methoxy on $\mathrm{Ni}(111)$ ", submitted to Phys. Rev. Lett.

\section{PLANS FOR THE FUTURE}

Several key experiments are planned for the future. These include:

1. Study of the $N i(100)$ and $N i(110)$ Surfaces in the Activation of Methane 
As indicated above, and in agreement with molecular beam experiments, we have demonstrated in a bulb experiment that methane is activated on the Ni(111) surface by means of a direct process in which heated gas phase methane is responsible for $\mathrm{C}-\mathrm{H}$ bond scission at the $\mathrm{Ni}(111)$ surface. We wish to carry out this experiment with the rougher $\mathrm{NI}$ single crystal surfaces, testing whether the moblle precursor mechanism may become operative on these rougher surfaces. Finding a mobile precursor mechanism would indicate that the barrier for activation has probably decreased compared to the barrier on smooth $N i(111)$, or that the adsorption energy of the precursor species is greater on the rougher $\mathrm{Ni}$ surfaces.

\section{Study of $\mathrm{C}-\mathrm{H}$ Bond Softening in Adsorbed Cyclohexane on $\mathrm{Ni}(111)$.}

The use of reflection IR (IRAS) methods should permit us to measure the $\mathrm{C}-\mathrm{H}$ bond softening for $\mathrm{C}-\mathrm{H}$ bonds projecting toward a metal surface. This could be the first step in the chemical activation of $\mathrm{C}-\mathrm{H}$ bonds by interaction with a metal, leading to $\mathrm{C}-\mathrm{H}$ bond scission. We will adsorb cyclohexane and its deuterium counterpart in monolayers and multilayers, looking at the range of the expected $\mathrm{C}-\mathrm{H}$ bond softening process induced by the metal. We also plan to block three-fold $\mathrm{Ni}(111)$ hole sites with chemisorbed hydrogen to determine whether this blocks $\mathrm{C}-\mathrm{H}$ bond softening.

\section{HIGHLIGHT}

There is one technical highlight which could have rather immediate practical application. We have found that it is possible to remove $0-H$ species from the alumina support of a rhodium catalyst, and to therefore prevent oxidative degradation of the Rh metal. This laboratory finding is now being tested at the GM automotive testing laboratory for its influence on the lifetime of actual automotive catalysts. Should the test prove favorable, the modification procedure could provide a means to enhance Rh catalyst lifetime in automotive catalysis. The cost of this form of catalysis is about $\$ 5$ blllion/year in the USA. A $20 \%$ extension of catalyst lifetime could therefore produce a savings of the order of $\$ 1$ billiton to the US public.

We have carried out successful laboratory studies on two methods to achieve Rh lifetime extension. One method involves the use of silation of the catalyst to remove $\mathrm{O}-\mathrm{H}$ groups; a second involves the use of alkali exchange with the $\mathrm{O}-\mathrm{H}$ groups to remove thell. A patent has been granted on the first method; application has been made for a second patent on the second method. These patents are owned by the University of Pittsburgh.

While it is too early to claim that a significant economic impact will be made, I will notify DOE imnediately upon hearing of positive results from the automotive testing. 

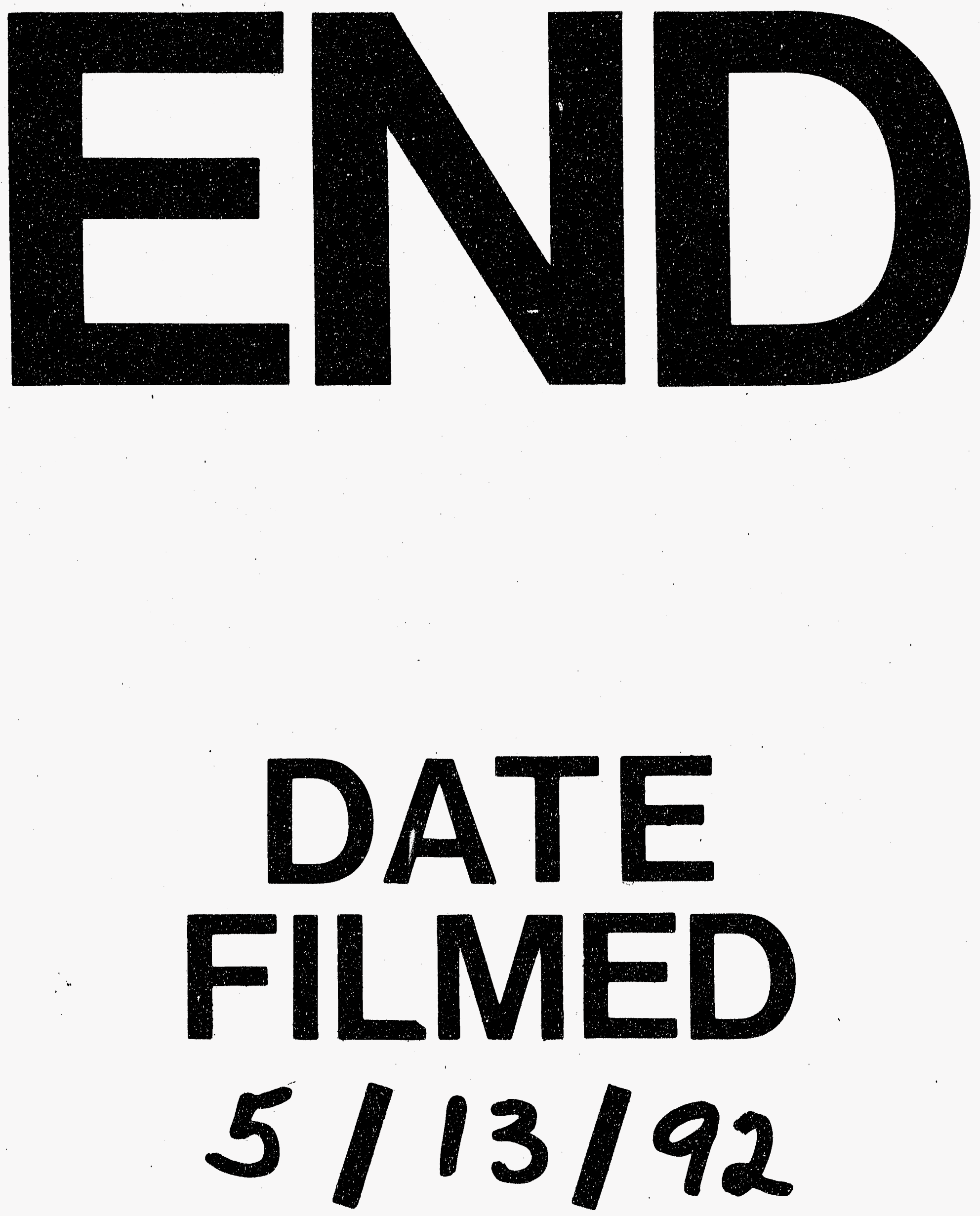

1 
